\title{
A Study on the Shape Repeatability of a Cable-Network Structure
}

\author{
By Hiroaki TANAKA ${ }^{1)}$ and Kenta SAITO ${ }^{1)}$ \\ ${ }^{1)}$ National Defense Academy of Japan, Yokosuka, Japan
}

(Received June 24th, 2011)

\begin{abstract}
In this study, the shape repeatability of cable-network structures is examined. Cables used for cable networks have nonlinearities between the tensile load and elongation. Therefore, the shapes of cable-network structures have some uncertainty, which leads to diminished shape repeatability. In order to clarify the influence of such nonlinearities, numerical simulations and experiments are carried out. The mechanical properties of the cables are experimentally investigated and their nonlinear characteristics are numerically modeled. The experimental model examined in our previous study is employed as the analysis model. The shape repeatability of the models caused by the nonlinear characteristics of cables and rigid body rotations of nodes are investigated through numerical simulations. The modeled nonlinear characteristics of the cables used in the numerical simulations are validated by comparing with experimental results.
\end{abstract}

Key Words: Space Structures, Space Antennas, Cable-Network Structure, Shape Repeatability

\section{Introduction}

High-performance space antennas are currently in demand for future communications and observations to obtain high gain and directivity and to ensure high frequency operation ${ }^{1,2)}$. In order to meet such demands, the antennas need to be large. However, large space antennas must also be lightweight and deployable because of the capacity limitations of launch vehicles. Meanwhile, high-precision antennas are required for the high-frequency operation of future satellite missions. Therefore, two structural performances, i.e., large dimensions and high accuracy, are required for future space antennas. However, it is difficult to make space antennas that are both large and precise $^{3)}$. In order to overcome this difficulty, several types of large deployable antennas have been studied and developed; in particular, deployable antennas consisting of cable networks are widely developed and used ${ }^{4-9}$.

Cables used for cable networks have nonlinearities, such as hysteresis and changes in natural length, between the tensile load and elongation. Figure 1 illustrates an example of these cable characteristics. In this paper, the term "changes in natural length" is used to describe elongation that remains in the cables after the cables are unloaded. A deployable antenna system comprising cable networks has latches in its deployment mechanisms. Thus, cable tensions vary owing to the effect of hysteresis while the antenna is deployed in orbit ${ }^{6}$. A deployable antenna consisting of cable networks is packaged in a launch vehicle after on-ground deployment tests. Accordingly, the shapes of the cable networks are affected by hysteresis and changes in the natural length of the cables, which leads to poor shape repeatability. Therefore, we must consider the influence of the nonlinear characteristics of cables in order to design high-precision antennas.

Although the errors caused by the shape repeatability of the deployable antennas have been observed in some studies ${ }^{4,5)}$ and deployment repeatability caused by joints has been investigated for high precision space structures ${ }^{10,11)}$, little attention has been given to the mechanisms via which cable nonlinearities affect the shape repeatability. However, it is necessary to consider the mechanisms for shape repeatability of a cable-network structure for next-generation antennas.

In our previous study, we experimentally investigated the shape repeatability of cable-network structures ${ }^{12,13)}$. In the experiments, repeated loads were applied to the experimental models and the shape repeatability of the cable-network structures was quantified. However, the mechanisms via which cable nonlinearities affect the shape repeatability of a cable-network structure have not been clarified.

In this study, a numerical model that includes the nonlinear characteristics of cables was developed and the mechanism was investigated through numerical simulations and experiments. The mechanical properties of the cables were experimentally investigated. In this study, we focused on the hysteresis and changes in the natural length of the cables among the nonlinear characteristics. The characteristics of hysteresis and changes in the natural length of cables were numerically modeled based on the experimental results.

The shape changes of the analysis models caused by repeated loads were investigated through numerical simulations. The experimental model examined in our previous study was employed as an analysis model in order to compare the results. The modeled nonlinear characteristics of cables used in the numerical simulations were validated by comparing them with experimental results that were obtained in our previous study ${ }^{13)}$.

\section{Mechanical Properties of Cables}

\subsection{Experimental investigation of mechanical properties of cables}

The mechanical properties of cables were examined to develop numerical models. In this study, twisted aramid fibers, which are used for some space applications, were employed as the members of the cable-networks. Load-strain curves were 
measured for 16 types of repeated loads. Five samples were tested for each type of repeated load. Each of the samples had a length of approximately $250 \mathrm{~mm}$. These test cases are summarized in Table 1.

One of the two types of load sets was applied to the samples to remove the initial elongation before the tests. Giannopoulos et al. revealed that the relationship between creep strain of aramid fibers and logarithmic time is practically linear ${ }^{14)}$. In this study, a load ( $50 \mathrm{~N}, 1$ month) is employed to remove the initial elongation as it is expected to decrease the rate of cable elongation to $1 / 720$ of that during the first hour. The aim of this study is to develop a numerical model for the investigation of shape repeatability. Therefore, another load $(10 \mathrm{~N}, 48 \mathrm{~h})$ was also applied to facilitate the experiments.

Samples were tested using a Shimadzu AG-X tensile test rig with flat grips (JT TOHSI) and a $100 \mathrm{~N}$ load cell (Tokyo Sokki TCLZ-100NA), as shown in Fig. 2. The load cycle was repeated 40 times for each test. The repeated tensile tests were carried out on the basis of JIS L1017 $7^{15)}$. A typical test result is shown in Fig. 1. The nonlinear behaviors that appear near the maximum loads are caused by the backlash of the flat grips.

Table 1. Test cases of repeated tensile tests.

\begin{tabular}{|c|c|c|c|}
\hline $\begin{array}{l}\text { Test } \\
\text { Case }\end{array}$ & $\begin{array}{c}\text { Maximum repeated } \\
\text { load, } \mathrm{T}[\mathrm{N}]\end{array}$ & $\begin{array}{c}\text { Load conditions for } \\
\text { removing initial } \\
\text { elongation }\end{array}$ & $\begin{array}{c}\text { Number of } \\
\text { samples }\end{array}$ \\
\hline 1 & 9 & \multirow{8}{*}{$10 \mathrm{~N}, 48 \mathrm{~h}$} & 5 \\
\hline 2 & 12.5 & & 5 \\
\hline 3 & 17 & & 5 \\
\hline 4 & 24 & & 5 \\
\hline 5 & 27.5 & & 5 \\
\hline 6 & 34 & & 5 \\
\hline 7 & 39 & & 5 \\
\hline 8 & 44 & & 5 \\
\hline 9 & 11 & \multirow{8}{*}{$\begin{array}{l}50 \mathrm{~N}, 720 \mathrm{~h} \\
(1 \mathrm{month})\end{array}$} & 5 \\
\hline 10 & 12 & & 5 \\
\hline 11 & 18 & & 5 \\
\hline 12 & 22 & & 5 \\
\hline 13 & 28 & & 5 \\
\hline 14 & 33 & & 5 \\
\hline 15 & 38 & & 5 \\
\hline 16 & 43 & & 5 \\
\hline
\end{tabular}

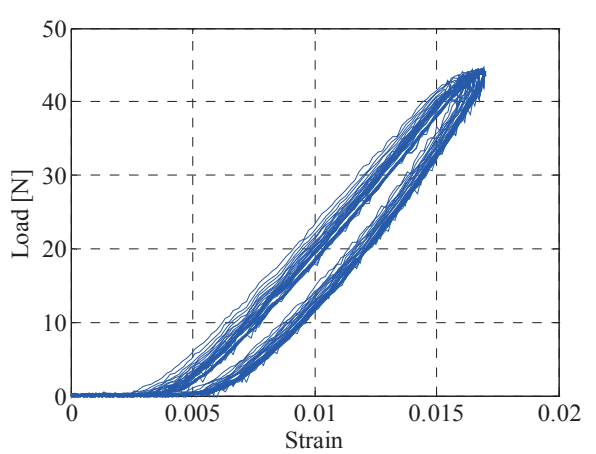

Fig. 1. Typical load-strain relationship for an aramid fiber (Test Case 8)

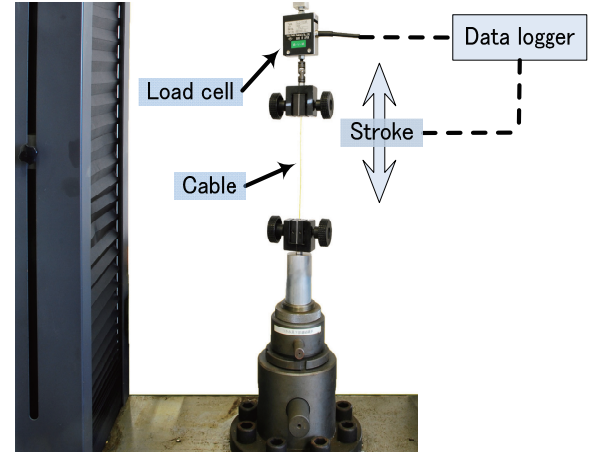

Fig. 2. Tensile testing rig and load cell.

\subsection{Modeling of the mechanical properties of cables}

The nonlinear characteristics of the cables were numerically modeled based on the experimental results. In this study, we focused on the hysteresis and changes in the natural length of cables among the nonlinear characteristics. The typical load-strain relationships caused by hysteresis and changes in the natural length are shown in Figs. 3 and 4, respectively. Figure 3 shows the first cycle, and Fig. 4 shows the first and the last cycles extracted from Fig. 1. Here, the phenomena caused by the hysteresis are modeled as changes in the EA value, which is the product of the elastic modulus (E) and the cable area (A), of the loading and unloading processes. The load-strain relationships are modeled via linear regression around 70 percent of the maximum load where the effect of nonlinear behaviors caused by the backlash of the flat grips is small. EA values and changes in the pseudo natural lengths of the cables were calculated from the modeled linear relationships for each load cycle of the samples. Here, the term "pseudo natural length" describes the length at zero load, as calculated by the modeled linear relationships. Figures 5 and 6 show the calculated changes in the pseudo natural lengths of the cables and EA values of the typical samples, respectively.

We can observe from these figures that the cables have nonlinear characteristics even though a large load was applied to the cable for a long time to remove the initial elongation. Here, we assume that the phenomena that cause the changes in the pseudo natural lengths after repeated loads are similar to those for the $\operatorname{creep}^{16)}$. Therefore, their relationship was modeled using the following equation:

$$
\varepsilon_{l 0}=\mathrm{A}_{\varepsilon l 0} \times \log (N)+\mathrm{B}_{\varepsilon l 0}
$$

The relationship between the EA values and load cycles were modeled using Eq. (2).

$\mathrm{EA}_{\text {Load or Unload }}=\mathrm{A}_{\mathrm{EA}} \times\left\{1-\exp \left(-\mathrm{B}_{\mathrm{EA}} \times \mathrm{N}\right)\right\}+\mathrm{C}_{\mathrm{EA}}$

where $N$ denotes the cycle number. $\varepsilon_{l 0}$ was defined as the ratio of the change in the pseudo natural length to the original natural length. $\mathrm{A}_{\varepsilon l 0}, \mathrm{~B}_{\varepsilon l 0}, \mathrm{~A}_{\mathrm{EA}}, \mathrm{B}_{\mathrm{EA}}$, and $\mathrm{C}_{\mathrm{EA}}$ are the parameters that are calculated for each sample by fitting the experimental data to Eqs. (1) and (2). The obtained approximation curves are shown in Figs. 5 and 6, and the calculated parameters are summarized in Figs. 7-11.

From these figures, some trends between the parameters 
and tensions can be observed. In this study, we assume linear relationships and define the functions of the relations from the parameters. The linear expressions of the parameters are summarized in Table 2. The shape repeatability of a cable-network structure can be investigated by using these modeled mechanical properties.

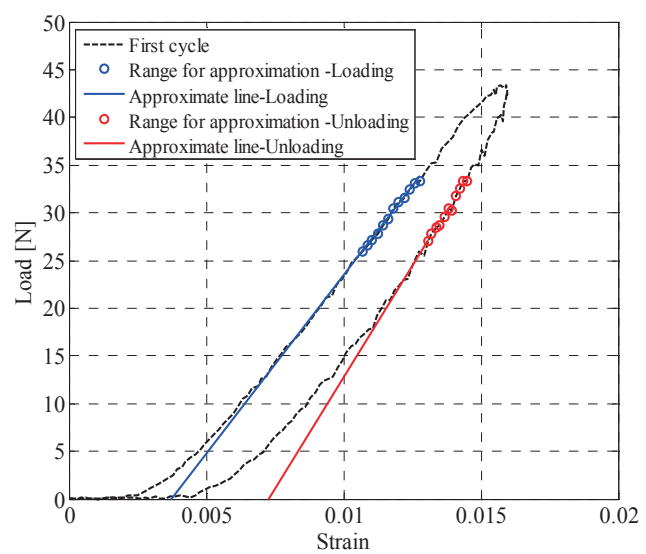

Fig. 3. Typical load-strain relationship caused by hysteresis.

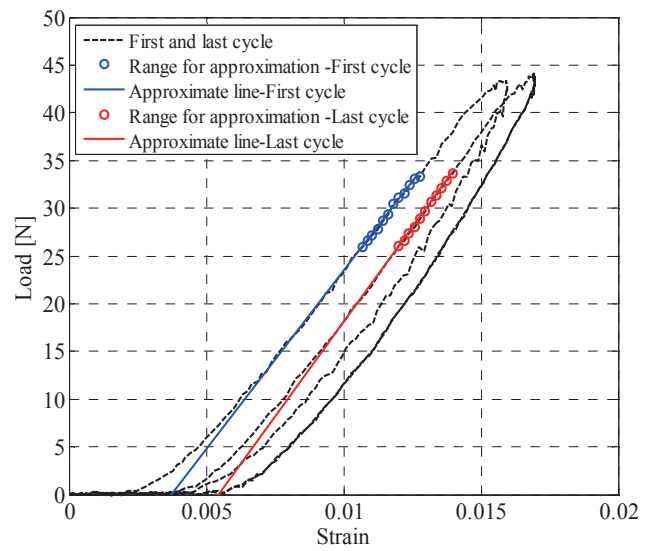

Fig. 4. Typical load-strain relationship caused by changes in the natural length of the cable.

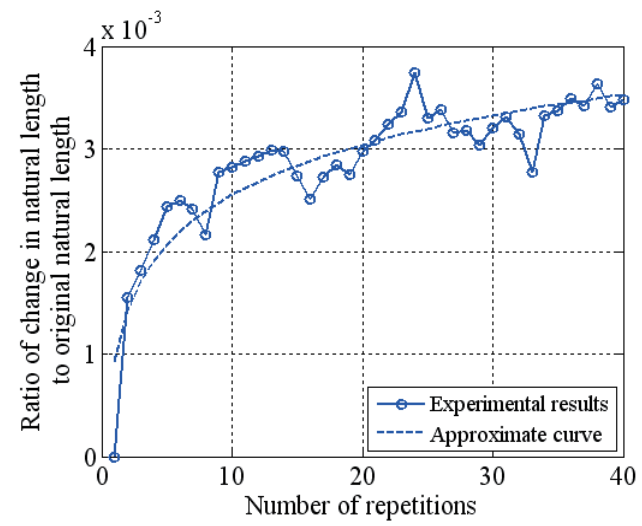

(One sample of test case 8:

A load of $10 \mathrm{~N}$ was applied for $48 \mathrm{~h}$ before the test)

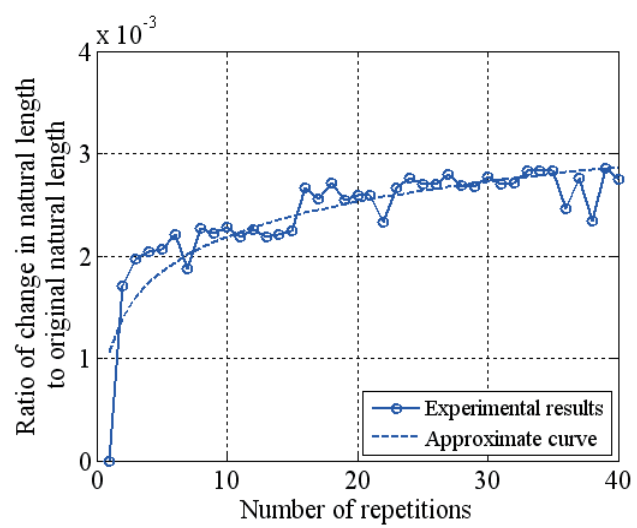

(One sample of test case 16:

A load of $50 \mathrm{~N}$ was applied for $720 \mathrm{~h}$ before the test)

Fig. 5. Relationship between changes in the pseudo natural length of a cable and load cycle.

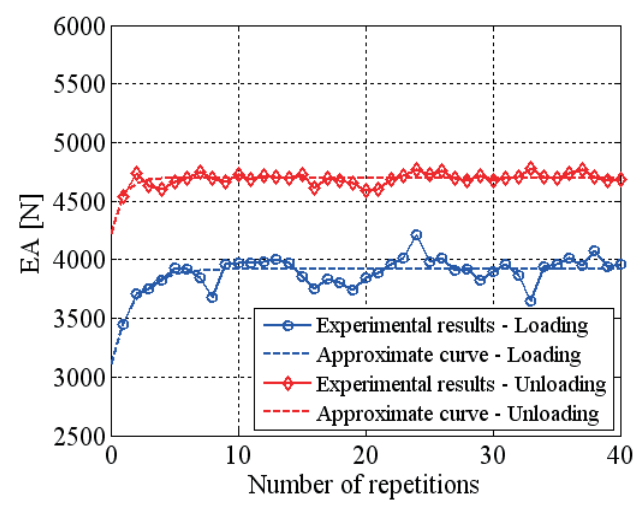

(One sample of test case 8:

A load of $10 \mathrm{~N}$ was applied for $48 \mathrm{~h}$ before the test)

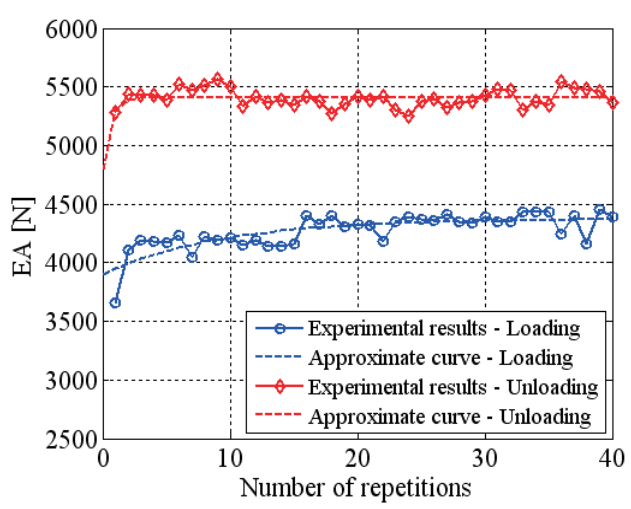

(One sample of test case 16:

A load of $50 \mathrm{~N}$ was applied for $720 \mathrm{~h}$ before the test)

Fig. 6. Relationship between EA values and load cycle. 


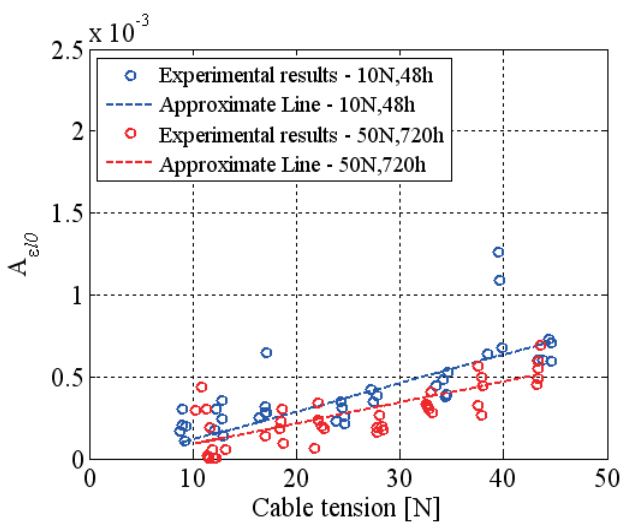

Fig. 7. $\mathrm{A}_{\varepsilon l 0}$ vs. cable tension.

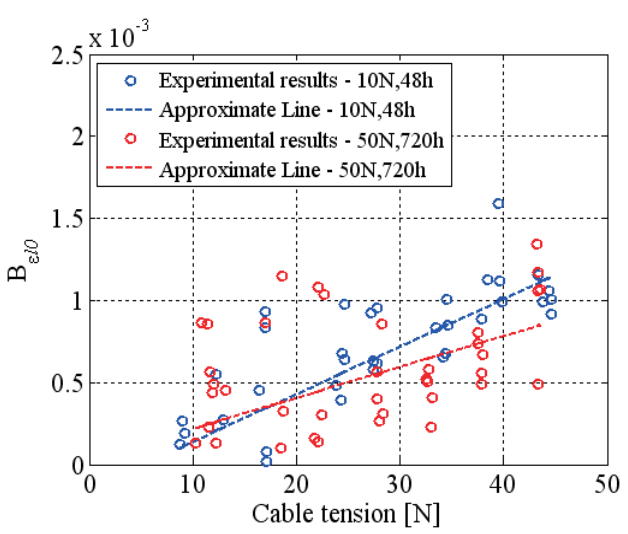

Fig. 8. B $\mathrm{B}_{\varepsilon l 0}$ vs. cable tension.

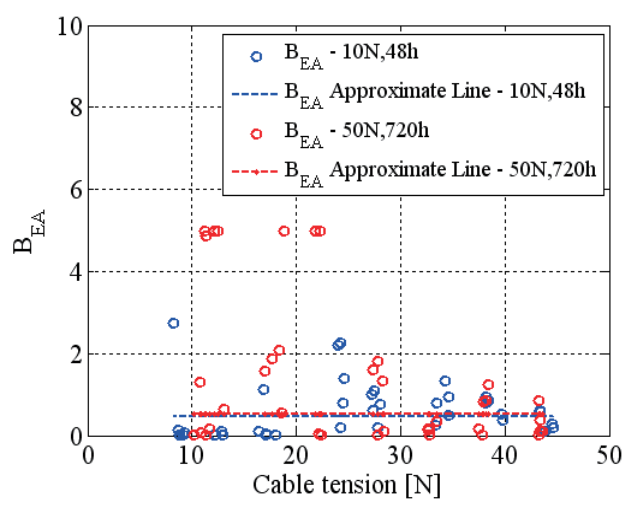

Fig. 9. $B_{\mathrm{EA}}$ vs. cable tension.

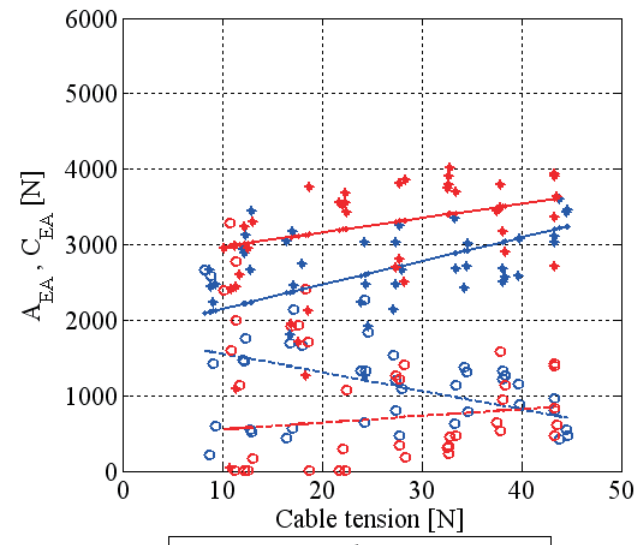

$$
\begin{aligned}
\circ & \mathrm{A}_{\mathrm{EA}}-10 \mathrm{~N}, 48 \mathrm{~h} \\
--- & \mathrm{A}_{\mathrm{EA}} \text { Approximate Line - 10N,48h } \\
\circ & \mathrm{A}_{\mathrm{EA}}-50 \mathrm{~N}, 720 \mathrm{~h} \\
--- & \mathrm{A}_{\mathrm{EA}} \text { Approximate Line - 50N,720h } \\
+ & \mathrm{C}_{\mathrm{EA}}-10 \mathrm{~N}, 48 \mathrm{~h} \\
- & \mathrm{C}_{\mathrm{EA}} \text { Approximate Line - 10N,48h } \\
+ & \mathrm{C}_{\mathrm{EA}}-50 \mathrm{~N}, 720 \mathrm{~h} \\
- & \mathrm{C}_{\mathrm{EA}} \text { Approximate Line - 50N,720h }
\end{aligned}
$$

Fig. 10. $\mathrm{A}_{\mathrm{EA}}$ and $\mathrm{C}_{\mathrm{EA}}$ vs. cable tension (Loading process).

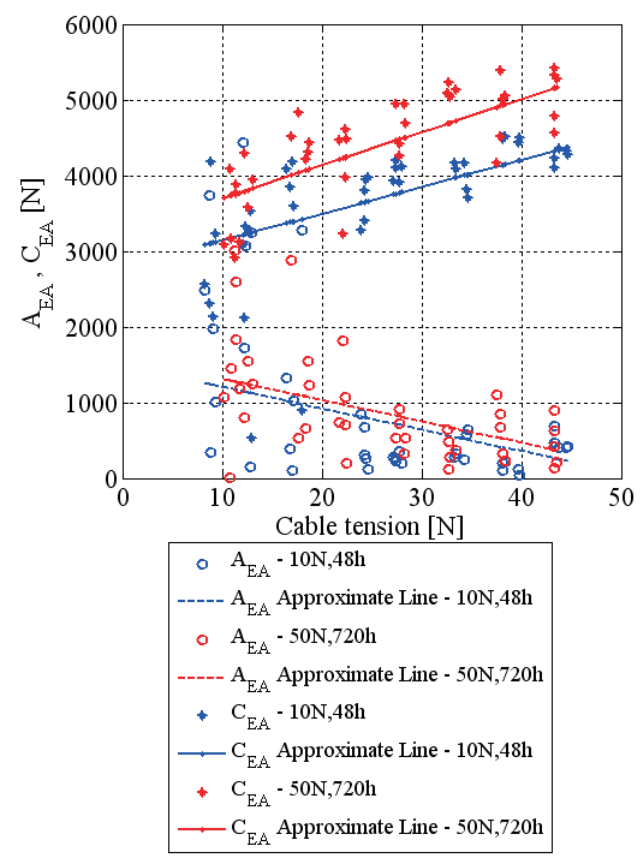

Fig. 11. $\mathrm{A}_{\mathrm{EA}}$ and $\mathrm{C}_{\mathrm{EA}}$ vs. cable tension (Unloading process). 
Table 2. Linear expression of the parameters of the cable mechanical properties.

\begin{tabular}{|c|c|c|c|c|}
\hline Parameters & \multicolumn{4}{|c|}{$\begin{array}{c}\text { Linear expression of parameters } \\
\text { (T: Amplitude of the repeated load) }\end{array}$} \\
\cline { 2 - 5 } & \multicolumn{2}{|c|}{$\begin{array}{c}\text { Load conditions } \\
10 \mathrm{~N}, 48 \mathrm{~h}\end{array}$} & \multicolumn{2}{c|}{$\begin{array}{c}\text { Load conditions } \\
50 \mathrm{~N}, 720 \mathrm{~h}\end{array}$} \\
\cline { 2 - 5 } & Loading & Unloading & Loading & Unloading \\
\hline $\mathrm{A}_{\varepsilon / 0}\left(\times 10^{-5}\right)$ & -5.65 & - & -3.71 & - \\
& $+1.73 \mathrm{~T}$ & & $+1.27 \mathrm{~T}$ & - \\
\hline $\mathrm{B}_{\varepsilon l 0}\left(\times 10^{-5}\right)$ & -15.0 & - & 3.01 & - \\
& $+2.90 \mathrm{~T}$ & & $+1.88 \mathrm{~T}$ & \\
\hline $\mathrm{A}_{E A}[\mathrm{~N}]$ & 1804 & 1409 & 463 & 1598 \\
& $-26.4 \mathrm{~T}$ & $-28.3 \mathrm{~T}$ & $+9.1 \mathrm{~T}$ & $-28.2 \mathrm{~T}$ \\
\hline $\mathrm{B}_{E A}$ & 0.45 & 0.47 & 0.53 & 0.31 \\
\hline$C_{E A}[\mathrm{~N}]$ & 1837 & 2790 & 2776 & 3257 \\
& $+31.5 \mathrm{~T}$ & $+35.4 \mathrm{~T}$ & $+19.3 \mathrm{~T}$ & $+43.9 \mathrm{~T}$ \\
\hline
\end{tabular}

\section{Shape Repeatability Analysis of a Cable-Network} Structure

\subsection{Analysis model}

To validate the developed model for the mechanical properties, the shape repeatability of a cable-network structure was numerically investigated and the results were compared with the experimental results obtained in our previous study ${ }^{13)}$. Experimental model type I, which was examined in our previous study, was employed as the analysis model. A schematic representation of the analysis model is shown in Fig. 12.

The model consists of eight cables and eight physical nodes. Here, the term "physical node" is used to describe the nodes of the models and is thereby distinguished from the "numerical node" used for numerical analysis. The four physical nodes located at the edge of the model are fixed nodes (node nos. 5-8), while the other four physical nodes located in the middle of the model are free nodes (node nos. 1-4). The analysis model is designed to represent a part of an antenna consisting of cable networks. The tensions and lengths of each cable of the analysis model are shown in Table 3. The mechanical properties model of the cables that had a load of $10 \mathrm{~N}$ applied for $48 \mathrm{~h}$ before the test are employed.

In order to investigate the influence of rigid body rotations of the physical nodes, two types of models, i.e., node model A and $\mathrm{B}$, of the physical nodes were employed for numerical analysis. In model A, a physical node was modeled by one numerical node, whereas in model B, it was modeled by three numerical nodes and three high stiffness bar elements. An outline of these node models is shown in Fig. 13. The mass of each physical node is $3.5 \mathrm{~g}$ and it is assumed that gravity is negative along the $\mathrm{Y}$ direction. The effect of gravity is considered for the comparison of the experimental results.

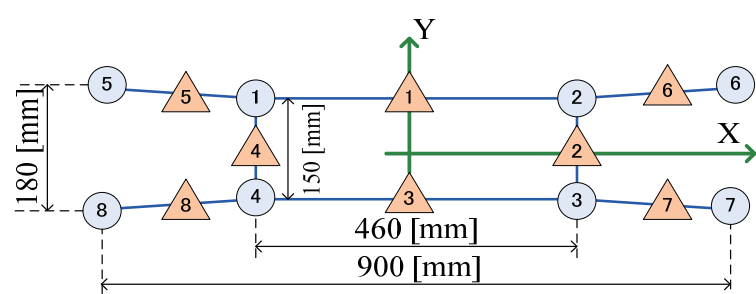

: Cable number $\bigcirc:$ Physical Node number

Fig. 12. Schematic representation of the analysis model.

Table 3. Tensions and the lengths of cables.

\begin{tabular}{cccc}
\hline Cable Number & 1,3 & 2,4 & $5-8$ \\
\hline Tension $[\mathrm{N}]$ & 24.94 & 1.70 & 25.00 \\
Length $[\mathrm{m}]$ & 0.45000 & 0.15000 & 0.22051 \\
\hline
\end{tabular}

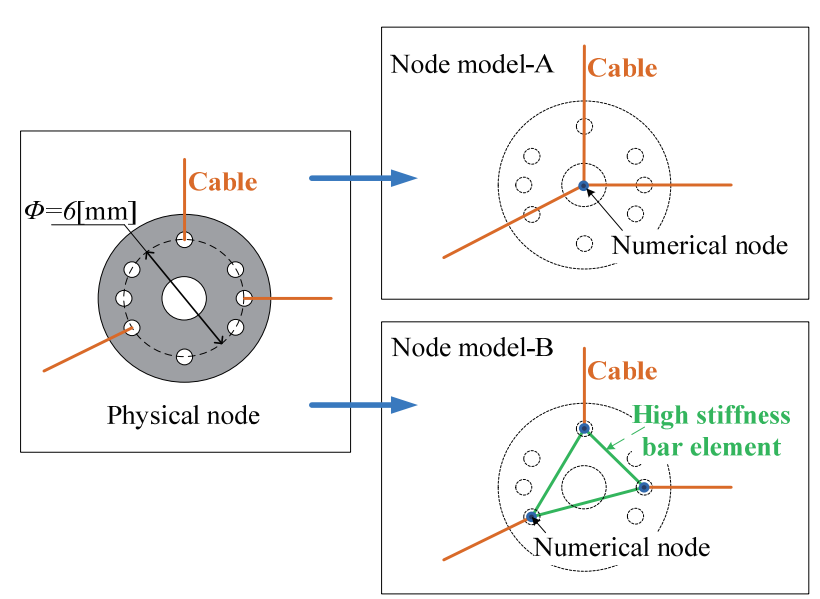

Fig. 13. Outline of model A and B of the physical nodes.

\subsection{Shape repeatability analysis}

Figure 14 shows a schematic diagram of the repeated loading procedure. Three states for repeated loading were assumed in the analysis: (a) a slackened state where the cable tensions are not applied, (b) a nominal state where the positions of the fixed nodes are at the designed position to achieve the designed shape of the cable-network, and (c) an excess pulling state where the positions of the right side fixed nodes are located $1 \mathrm{~mm}$ to the right of a nominal state. The excess pulling state simulates the latching of the antenna deployment mechanism. In each load cycle, it was assumed that the three states are repeated in the order of $(a) \rightarrow(b$ : loading $) \rightarrow(\mathrm{c}) \rightarrow$ (b: unloading) $\rightarrow$ (a), and the shapes of the analysis model were numerically analyzed at the state $b$ (loading/unloading). In a previous study, it was experimentally observed that the rate of the shape change in experimental model Type I becomes small after 10 repeated cycles. Therefore, in this study, the load cycle was repeated 21 times: initial shape plus 20 repeated load cycles. It was assumed that the initial lengths of the cables have random errors and the variance is $0.5 \mathrm{~mm}$. Typical results of the numerical simulations, for which the same random errors are given, are shown in Figs. 15 and 16. Figure 17 shows one 
example of the experimental results ${ }^{13)}$. In these figures, the displacements are multiplied 500 times to improve the clarity. From these figures, it is evident that the movements of the nodes in the numerical simulations and the experimental results indicate similar directions and amplitudes. The node movements during the loading and unloading processes, which are indicated by the blue and green marks, respectively, are almost same. This indicates that the changes in the natural lengths of the cables cause a larger displacement than the hysteresis. By comparing Figs. 15 and 16, a small but significant influence of the rigid body rotations of the physical nodes was observed.

To investigate the influence of gravity, a numerical simulation without gravity was carried out. The node movements during the loading process were simulated using node model $\mathrm{B}$. The movement of the nodes with and without gravity is summarized in Fig. 18. It is evident from this figure that the influence of gravity is negligible in this analysis model because the mass of the node is small.

The numerical simulations were carried out 1000 times using node model $B$. Their results and those of the experiments $^{13)}$ are summarized in Fig. 19, which shows the root sum square (RSS) of the free-node displacements. The mean values and mean values plus one standard deviation of the results of numerical simulations are also plotted. From this figure, we observed that the majority of the experimental results are within one standard deviation of the results of numerical simulations. We conclude from those results that the modeled nonlinear characteristics of cables are valid to examine shape the repeatability of a cable network structure.

(a) Slackened state
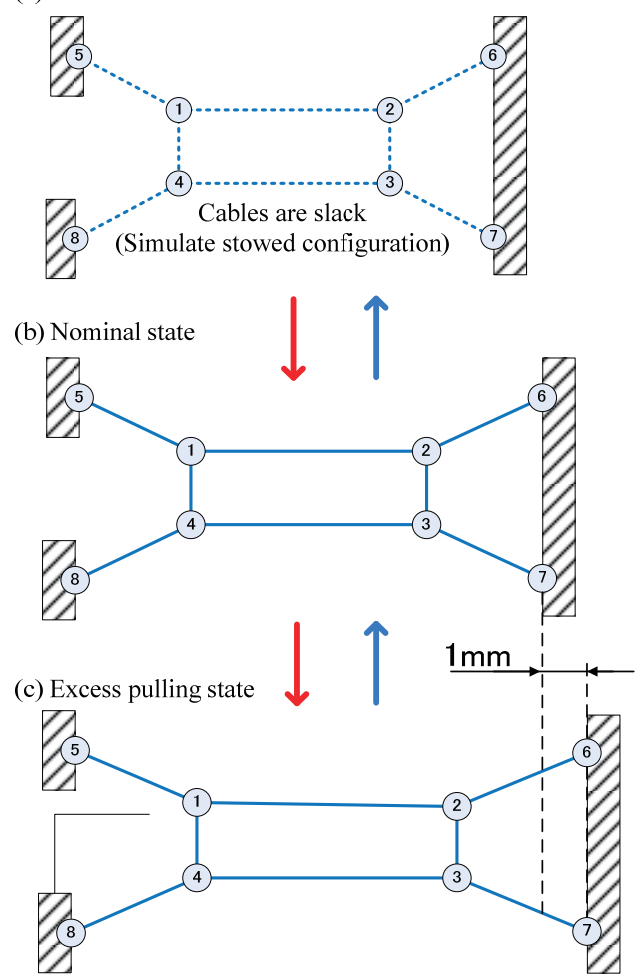

Fig. 14. Schematic diagram of repeated loading procedure.

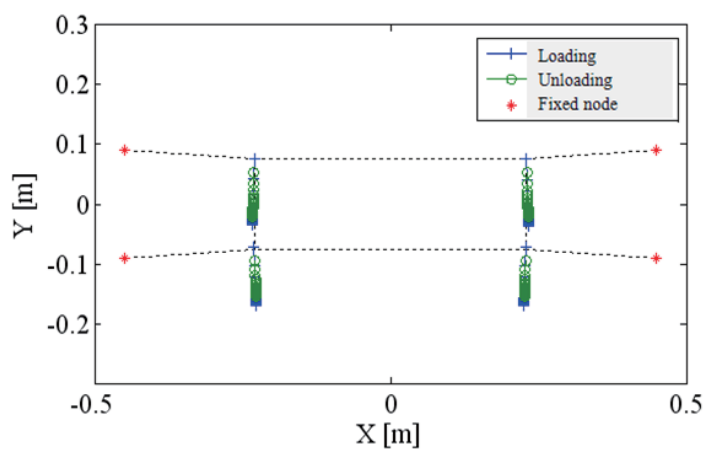

Fig. 15. Typical result of the numerical simulation (node model A).

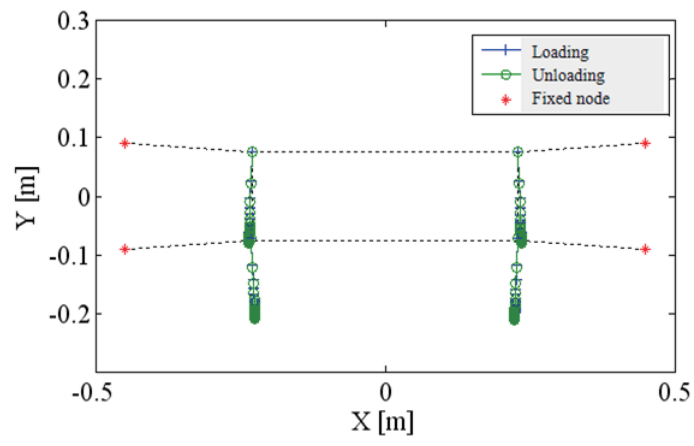

Fig. 16. Typical result of the numerical simulation (node model B).

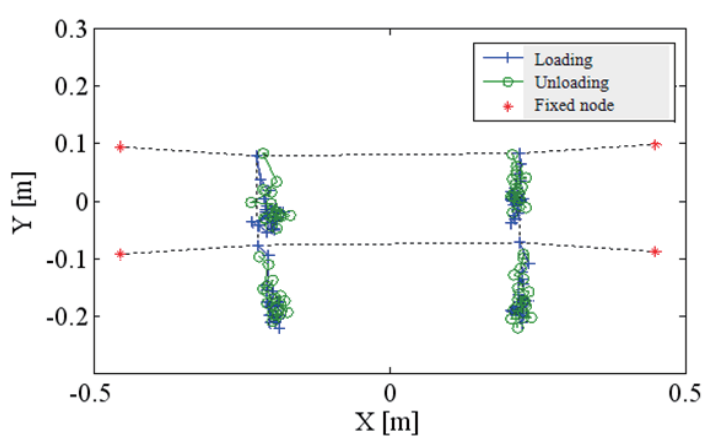

Fig. 17. Shape changes of the experimental model ${ }^{13)}$.

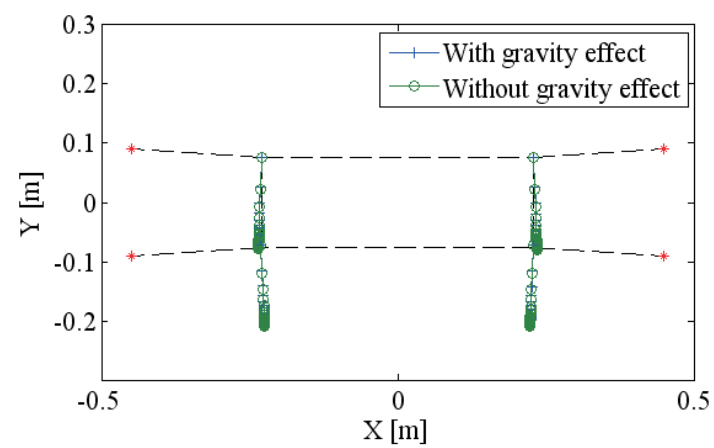

Fig. 18. Movement of nodes with and without gravity. 


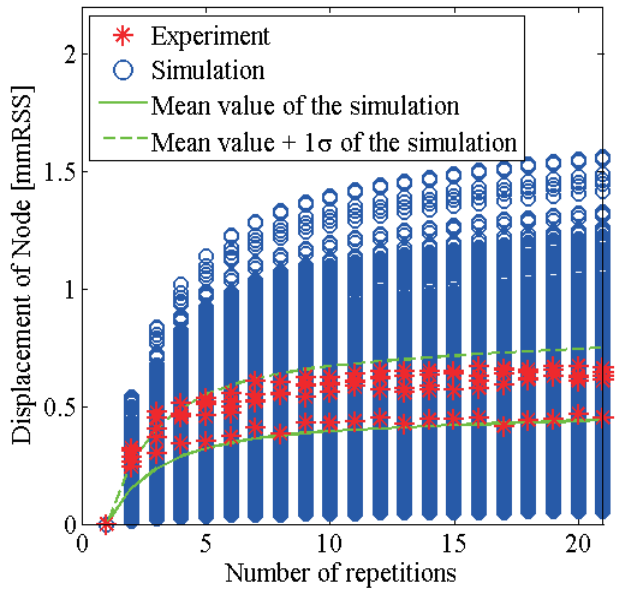

Fig. 19. Root sum square of the node displacements of the numerical and experimental results.

\section{Conclusion}

In this study, the shape repeatability of cable network structures was examined. Numerical simulations and experiments were carried out to clarify the influence of such nonlinearities. The mechanical properties of the cables were experimentally investigated and the nonlinear characteristics of the cables were numerically modeled. The experimental model examined in our previous study was employed as the analysis model in order to compare the results. These models were designed to represent a part of an antenna consisting of cable networks. The shape changes of the models caused by repeated loads were investigated through numerical simulations, and the modeled nonlinear characteristics of the cables used in the numerical simulation were validated by comparing them with experimental results. The influence of the nonlinearities of the cables on a full model of a cable-network antenna is able to be examined using the modeled nonlinear characteristics of the cables.

\section{Acknowledgement}

This work was supported by KAKENHI (Grant-in Aid for Young Scientists (B), No. 22760631).

\section{References}

1) Angeletti, P., Lisi, M. and Lucchi, G.: Satellite Antennas for Broadband Mobile Communications Missions, 21st AIAA International Communications Satellite Systems Conference and Exhibit, 2003, AIAA-2003-2222.

2) Hirabayashi, H.: Japanese Second Generation Space VLBI Mission and New Technologies, New technologies in VLBI, Proceedings of a symposium of the International VLBI Service for Geodesy and Astrometry, ASP Conference Series, 306 (2003), pp. 306-330.

3) Meguro, A., Harada, S. and Watanabe, M.: Key Technologies for High-Accuracy Large Mesh Antenna Reflectors, Acta Astronautica, 53(2003), pp. 899-908.

4) Natori, M. C., Takano, T., Noda, T., Tashima, T. and Tabata, M.: Ground Adjustment Procedure of a Deployable High Accuracy Mesh Antenna for Space VLBI Mission, 39th AIAA/ASME/ASCE/AHS/ASC Structures, Structural Dynamics, and Materials Conference \& Exhibit, 1998, AIAA-98-1923.

5) Thomson, M. W.: Astromesh Deployable Reflectors for $\mathrm{Ku}-$ and Ka-Band Communications Satellites, 20th AIAA International Communications Satellite System Conference and Exhibit, 2002, AIAA-2002-2032.

6) Takano, T., Natori, M. C., Ohnishi, A., Miyoshi, K., Inoue, T., Mizutamari, H., Yanai, H. and Hirosawa, H.: Large Deployable Antenna with Cable Constitution for Satellite-Use, IEICE Transactions, J-81-B-II (1998), pp. 673-681 (in Japanease).

7) Meguro, A., Tsujihata, A., Hamamoto, N. and Homma, M.: Technology Status of the $13 \mathrm{~m}$ Aperture Deployment Antenna Reflectors for Engineering Test Satellite VIII, Acta Astronautica, 47(2000), pp. 147-152.

8) Natori, M. C., Hirabayashi, H., Okuizumi, N., Iikura, S. and Nakamura, K.: Modular Antenna Concept Consisted of Radial Ribs and Hoop Cables for Space VLBI Mission, 25th ESA Antenna Workshop on Satellite Antenna Technology, 2002.

9) Ueba, M., Tanaka, H., Kawakami, Y. and Ohtomo, I.: Study on On-Board Large Mesh Antenna Reflector with High Surface Accuracy, IEICE Transactions, J76-B-II (1993), pp. 468-475 (in Japanease).

10) Heald, J.C.: Deployment Repeatability in Mechanically Jointed Precision Structures, University of Colorado Doctoral Dissertation, Report No. CU-CAS-03-06, 2003.

11) Domber, J. L., Hinkle, J.D., Peterson, L.D. and Warren, P.A. : Dimensional Repeatability of an Elastically Folded Composite Hinge for Deployed Spacecraft Optics, Journal of spacecraft and rockets, 39(2002), pp. 646-652.

12) Saito, K., Tanaka, H. and Moriya, K.: Study on Shape Repeatability of a Flexible Space Structure with Hysteresis, 61st International Astronautical Congress, 2010, IAC-10-C2.2.8.

13) Saito, K., Tanaka, H. and Moriya, K.: Study on Shape Repeatability of a Flexible Space Structure Considering Nonlinearities of Cables, 26th Symposium on Aerospace Structure and Materials, 2010, B18 (in Japanease).

14) Giannopoulos, I.P. and Burgoyne C.J.: Viscoelasticity of Kevlar 49 fibres, 16th National Conference on Concrete Structures, Pafos, Cyprus, 2009.

15) Test Methods for Chemical Fibre Tire Cords, Japanese Industrial Standard, JIS L 1017.

16) Fette, R.B. and Sovinski, M.F.: Vectran fiber time-dependent behavior and additional static loading properties, 2004, NASA TM-2004-212773. 